\title{
Plakophilin-2 Gene Could Be a Causative Factor in Arrhythmogenic Right Ventricular Cardiomyopathy
}

\author{
Susumu Adachi, MD, PhD; Mitsuaki Isobe, MD, PhD
}

A rrhythmogenic right ventricular cardiomyopathy (ARVC) is generally characterized by RV enlargement and dysfunction associated with fibrofatty replacement of the myocardial tissue. ${ }^{1}$ The resulting disruption of normal cardiac architecture can cause severe RV dysfunction, as well as life-threatening arrhythmias and sudden cardiac death. ${ }^{2}$ ARVC is familial in up to $50 \%$ of cases and is an inherited cardiomyopathy estimated to affect approximately 1 in 5,000 individuals. ${ }^{3}$ ARVC is generally transmitted as an autosomal dominant trait, although there are some cases of autosomal recessive inheritance. Studies of individuals from the Greek island of Naxos with an autosomal recessive syndrome characterized by the triad of ARVC with diffuse nonepidermolytic palmoplantar keratoderma and woolly hair led to the identification of the first causative gene of an ARVCassociated disorder. Initial mapping of this disorder pointed to the chromosomal locus 17q21, and candidate-gene sequencing within this region revealed a homozygous deletion in the junctional plakoglobin gene., ${ }^{4,5}$ In contrast, a study of a German family reported on the first-identified dominantly inherited junctional plakoglobin gene mutation to cause nonsyndromic ARVC. ${ }^{6}$ In 2000 , homozygosity mapping led to the discovery of a desmoplakin gene mutation in three Ecuadorian families with Carvajal syndrome. ${ }^{7}$ These mutational discoveries in the plakoglobin and desmoplakin genes, which express functionally related proteins, prompted attention to be focused on the desmosome in the ARVC pathogenesis. Plakophilin-2 (PKP2), an armadillo protein family, interacts directly with plakoglobin and desmoplakin. Subsequent sequencing of the PKP2 gene in 120 unrelated probands with ARVC revealed heterozygous mutations in 32 individuals. ${ }^{8}$ This discovery of $P K P 2$ mutations led to a breakthrough in the unraveling of the genetics of ARVC and supported the idea that ARVC might be a desmosomal disease.

\section{Article p 189}

Desmosomes are most prevalent in tissues exposed to friction and shearing stress, such as the myocardium and epithelium, where they play a key role in imparting mechanical strength, both via cell-cell adhesion and through transmission of force between the junctional complex and the intermediate filaments in the cytoskeleton. ${ }^{9}$ Within the desmosomes, cadherins interact with armadillo proteins, which for their part are connected to plakins. ${ }^{10}$ The latter anchor desmosomes to intermediated filaments, mainly desmin, thereby forming a 3dimensional scaffolding that provides tissues with mechanical strength. Although desmosomal proteins are widely expressed, mutations in specific components lead to only myocardial dysfunction, because some are specifically expressed in the myocardial tissue. Desmosome mutations are currently believed to exert pathogenic effects at different levels. One is at the desmosome composition and functional level. The other levels relate to intercalated discs and $\mathrm{Wnt} / \beta$-catenin signaling. ${ }^{11} \mathrm{At}$ all levels, desmosome impairment is believed to cause tissue to be predisposed to damage under conditions of mechanical stress, leading to the disruption and subsequent degeneration of cardiomyocytes. Subsequently, mechanical stress induces apoptosis and replacement by fibrofatty tissue. This may lead to variations in conduction properties, resulting in the initiation of ventricular tachycardia.

Dalal et al demonstrated that patients with $P K P 2$ mutations presented at an earlier age than those without mutations $(28 \pm 11$ vs. $36 \pm 16$ years). In addition, the median cumulative symptom-free and arrhythmia-free survival rate was lower in $P K P 2$ mutation carriers than that among non-carriers ( 32 vs. 42 years, and 34 vs. 46 years, respectively). ${ }^{12}$ However, other groups did not identify significant differences between carriers and non-carriers of the PKP2 mutation with respect to average age at initial presentation, or a family history of sudden cardiac death. ${ }^{13}$ In addition, non-desmosomal genes, cardiac ryanodine receptor, and transforming growth factor- $\beta 3$, have been elucidated in inherited ARVC families, suggesting that different pathways may lead to myocyte apoptosis and degeneration.,14 Furthermore, genetic mutations in ARVC-related genes demonstrate incomplete penetrance and variable expressivity, implicating environmental factors in the etiology of this disease.

In this issue of the Journal, Zhang et al examine the mutations of $P K P 2$ in an autopsied heart of an ARVC subject and in autopsy-negative sudden-death patients. They conclude that $P K P 2$ mutations could be found at an almost equal rate as that of sudden unexpected death rates with negative autopsy patients, as well as ARVC patients. The linkage between ARVC and PKP2 may not be causal, but rather related to

The opinions expressed in this article are not necessarily those of the editors or of the Japanese Circulation Society.

Received November 14, 2011; accepted November 14, 2011; released online December 3, 2011

Department of Cardiovascular Medicine, Shuwa General Hospital, Saitama (S.A.); Department of Cardiovascular Medicine, Tokyo Medical and Dental University, Tokyo (M.I.), Japan

Mailing address: Susumu Adachi, MD, PhD, Department of Cardiovascular Medicine, Shuwa General Hospital, 1200 Yahara-shinden,

Kasukabe, Saitama 344-0035, Japan. E-mail: suadachi-circ@umin.ac.jp

ISSN-1346-9843 doi:10.1253/circj.CJ-11-1315

All rights are reserved to the Japanese Circulation Society. For permissions, please e-mail: cj@j-circ.or.jp 
an association between $P K P 2$ mutations and arrhythmias. To summarize, $P K P 2$ mutations are probably not specific to ARVC and may result in sudden unexpected death because of life-threatening arrhythmias. The authors conclude that the link between ARVC and desmosomal mutations may not be causal, but related to an association between defective desmosomal proteins and arrhythmias. ${ }^{15}$ This paper raises the question as to whether a $P K P 2$ mutation may be a causative factor involved in ARVC. Further studies are required to clarify whether or not the PKP2 is responsible for the onset of ARVC.

\section{References}

1. Van Tintelen JP, Hofstra RM, Wiesfeld AC, van den Berg MP, Hauer RN, Jongbloed JD. Molecular genetics of arrhythmogenic right ventricular cardiomyopathy: Emerging horizon? Curr Opin Cardiol 2007; 22: 185-192.

2. Komura M, Suzuki J, Adachi S, Takahashi A, Otomo K, Nitta J, et al. Clinical course of arrhythmogenic right ventricular cardiomyopathy in the era of implantable cardioverter-defibrillators and radiofrequency catheter ablation. Int Heart J 2010; 51: 34-40.

3. Awad MM, Calkins H, Judge DP. Mechanisms of disease: Molecular genetics of arrhythmogenic right ventricular dysplasia/cardiomyopathy. Nat Clin Pract Cardiovasc Med 2008; 5: 258-267.

4. Coonar AS, Protonotarios N, Tsatsopoulou A, Needham EW, Houlston RS, Cliff S, et al. Gene for arrhythmogenic right ventricular cardiomyopathy with diffuse nonepidermolytic palmoplantar keratoderma and woolly hair (Naxos disease) maps to $17 \mathrm{q} 21$. Circulation 1998; 97: 2049-2058.

5. McKoy G, Protonotarios N, Crosby A, Tsatsopoulou A, Anastasakis A, Coonar A, et al. Identification of a deletion in plakoglobin in arrhythmogenic right ventricular cardiomyopathy with palmoplantar keratoderma and woolly hair (Naxos disease). Lancet 2000; 355: $2119-2124$.

6. Asimaki A, Syrris P, Wichter T, Matthias P, Saffitz JE, McKenna WJ. A novel dominant mutation in plakoglobin causes arrhythmogenic right ventricular cardiomyopathy. Am J Hum Genet 2007; 81: 964973.

7. Norgett EE, Hatsell SJ, Carvajal-Huerta L, Cabezas JC, Common J, Purkis PE, et al. Recessive mutation in desmoplakin disrupts desmoplakin-intermediate filament interactions and causes dilated cardiomyopathy, woolly hair and keratoderma. Hum Mol Genet 2000; 9: $2761-2766$.

8. Gerull B, Heuser A, Wichter T, Paul M, Basson CT, McDermott DA, et al. Mutations in the desmosomal protein plakophilin-2 are common in arrhythmogenic right ventricular cardiomyopathy. Nat Genet 2004; 36: 1162 - 1164 (erratum Nat Genet 2005; 37: 106).

9. Sen-Chowdhry S, Syrris P, McKenna WJ. Role of genetic analysis in the management of patients with arrhythmogenic right ventricular dysplasia/cardiomyopathy. J Am Coll Cardiol 2007; 50: 1813-1821.

10. Garrod DR, Merritt AJ, Nie Z. Desmosomal cadherins. Curr Opin Cell Biol 2002; 14: 537-545.

11. Garcia-Gras E, Lombardi R, Giocondo MJ, Willerson JT, Schneider MD, Khoury DS, et al. Suppression of canonical Wnt/beta-catenin signaling by nuclear plakoglobin recapitulates phenotype of arrhythmogenic right ventricular cardiomyopathy. J Clin Invest 2006; 116: 2012-2021.

12. Dalal D, Molin LH, Piccini J, Tichnell C, James C, Bomma C, et al. Clinical features of arrhythmogenic right ventricular dysplasia/cardiomyopathy associated with mutations in plakophilin-2. Circulation 2006; 113: 1641-1649.

13. Van Tintelen JP, Entius MM, Bhuiyan ZA, Jongbloed R, Wiesfeld $\mathrm{AC}$, Wilde AA, et al. Plakophilin-2 mutations are the major determinant of familial arrhythmogenic right ventricular dysplasia/cardiomyopathy. Circulation 2006; 113: 1650-1658.

14. Tiso N, Stephan DA, Nava A, Bagattin A, Devaney JM, Stanchi F, et al. Identification of mutations in the cardiac ryanodine receptor gene in families affected with arrhythmogenic right ventricular cardiomyopathy type 2 (ARVD2). Hum Mol Genet 2001; 10: 189-194.

15. Zhang M, Tavora F, Oliveira JB, Li L, Franco M, Fowler D, et al. PKP2 mutations in sudden death from arrhythmogenic right ventricular cardiomyopathy (ARVC) and sudden unexpected death with negative autopsy (SUDNA). Circ J 2012; 76: 189-194. 